\title{
Room Temperature Growth of Ultra-Porous Hot-Wire Deposited Tantalum Pentoxide
}

\author{
Giorgos Papadimitropoulos ${ }^{1 *}$, Maria Vasilopoulou1, Nikos Vourdas ${ }^{1}$, Dimitris N. Kouvatsos ${ }^{1}$, \\ Kostas Giannakopoulos ${ }^{1}$, Stella Kennou², Dimitris Davazoglou'
}

\author{
${ }^{1}$ Institute of Nanoscience and Nanotechnology, NCSR Demokritos POB 60228, Agia Paraskevi, Attiki 15310, Greece \\ ${ }^{2}$ Department of Chemical Engineering, University of Patras, Patra 26500, Greece \\ *Corresponding author: E-mail: g.papadimitropoulos@inn.demokritos.gr
}

Received: 02 October 2018, Revised: 31 October 2018 and Accepted: 05 November 2018

DOI: $10.5185 /$ amlett.2019.2283

www.vbripress.com/aml

\begin{abstract}
Tantalum pentoxide films were deposited on $\mathrm{Si}$ substrates at room temperature, by heating metallic filaments at temperatures below $600{ }^{\circ} \mathrm{C}$, at a pressure of 1 Torr in $\mathrm{O}_{2}$ environment. This deposition method can be applied for all metallic oxides having higher vapor pressure than the corresponding metal. These $\left(\mathrm{hwTa}_{2} \mathrm{O}_{5}\right)$ films were composed by amorphous material (as revealed by XRD measurements) and were found to be highly transparent within the range 350-1000 nm. Spectroscopic ellipsometry measurements have shown that the real part of the refractive index (n) of hwTa $\mathrm{O}_{5}$ films depends on the deposition time and has a value below 1.5. As shown by scanning electron microscopy (TEM) measurements, these grains were composed by others with dimensions near $5 \mathrm{~nm}$ and with voids between them. The above microscopy measurements explain the high porosity of hwTa $\mathrm{O}_{5}$ films. Moreover, hwTa $\mathrm{O}_{5}$ films were also characterized by XPS and UPS measurements and the stoichiometric composition of the deposited films was determined. Copyright @ VBRI Press.
\end{abstract}

Keywords: Thin film, hot-wire deposition, tantalum pentoxide, room temperature growth.

\section{Introduction}

There is currently much need for high-k dielectric materials, as they are vital for the development of nanosize semiconducting components being developed in transition from microsize dimensions following Moore's Law [1, 2]. Many researchers have investigated suitable high-k dielectric materials in order to replace the well-known silicon dioxide, as its leakage current is too large at thickness down to $1.4 \mathrm{~nm} \mathrm{[3].} \mathrm{A}$ few authors have recently reported that materials such as hafnium dioxide $\left(\mathrm{HfO}_{2}\right)$ [4-6] and zirconium dioxide $\left(\mathrm{ZrO}_{2}\right)$ [7-9], with high dielectric constants of 20 and 23, respectively, are advantageous in capacitive applications and especially in leakage current dependent applications, such as portable (batteryoperated) devices. However, research on one particular type of dielectric remains relatively rare. Tantalum pentoxide $\left(\mathrm{Ta}_{2} \mathrm{O}_{5}\right)$ with high-k relative dielectric constant (27) has shown great thermal stability, high mobility and low electrical defect densities $[10,11]$. It has been recognized as an attractive material for applications in coatings $[\mathbf{1 0}, \mathbf{1 1}]$, catalysts [12], electronic circuitry [12], and it is utilized in capacitors [11-13] due to its high dielectric constant. It has also been reported as a very promising candidate for capacitive memories [19], optoelectronic applications as light waveguides [14-16], and in optical devices as an antireflection or birefringent coating and as a component of multilayer interference filters $[\mathbf{1 7}, \mathbf{1 8}, \mathbf{2 0}$, 22]. There are many different methods for the deposition of $\mathrm{Ta}_{2} \mathrm{O}_{5}$ films including electron beam evaporation [12, 20-22], anodization [23], chemical vapor deposition (CVD) in its numerous configurations (thermal, low-pressure, plasma-enhanced, photoassisted, metal-organic) $[\mathbf{1 2}, \mathbf{1 3}, \mathbf{2 4 - 2 7}]$, reactive sputtering [12, 14-16, 28, 29], ion beam sputter deposition [30], sol-gel spin coating $[\mathbf{1 2}, \mathbf{3 1}, \mathbf{3 2}]$, atomic layer deposition $[\mathbf{1 2}, \mathbf{3 3}]$ and pulsed laser deposition (PLD) $[\mathbf{1 0}, \mathbf{1 1}]$.

In this work we report on porous $\mathrm{Ta}_{2} \mathrm{O}_{5}$ films grown at room temperature, exhibiting high optical transmission and refractive index near and below 1.5 within the visible range. These films are deposited very easily compared to other methods using a heated metallic filament under vacuum. This deposition method can be applied for all metallic oxides having higher vapor pressure than the corresponding metal. This method keeps the substrate at room temperature rendering the deposition method suitable for using organic and plastic substrates, while allowing for fine film thickness control that can yield ultra-thin films. At the same time, this technique offers a fast process turnaround and economical operation compared to other deposition methods. 


\section{Experimental}

$\mathrm{Ta}_{2} \mathrm{O}_{5}$ films were deposited by heating a tantalum filament in a vacuum chamber (this is why the deposited films are named hereafter hot-wire tantalum pentoxide, $\mathrm{hwTa} \mathrm{O}_{5} \mathrm{O}_{5}$, films) at filament temperatures lower than $600{ }^{\circ} \mathrm{C}$. hwTa $2 \mathrm{O}_{5}$ films were deposited on $\mathrm{Si}$ pieces with dimensions of $2 \times 2 \mathrm{~cm}^{2}$ cut from (100) $\mathrm{Si}$ wafers. Before deposition the substrates were given a piranha clean, washed in ultra-pure water and dried in a nitrogen stream. Substrates were then placed in the deposition chamber on a copper susceptor located $5 \mathrm{~cm}$ below a tantalum filament fixed between two $\mathrm{Cu}$ current leads. After loading, the chamber was evacuated to below $10^{-2}$ Torr and then the pressure was stabilized to 1 Torr with the aid of a pressure control system comprising a baratron manometer, a butterfly valve and the electronic unit. After pressure stabilization, the filament was heated with the application of an AC $(50 \mathrm{~Hz})$ current (50V applied to the Ta filament). Deposition time variation was used to control the film thickness and the times used varied between 1 second to 60 seconds. During deposition the substrate remained near room temperature.

The deposited $\mathrm{hwTa}_{2} \mathrm{O}_{5}$ films were characterized with a variety of techniques, including spectroscopic ellipsometry within the $350-1000 \mathrm{~nm}$ range using a J. A. Woolam Inc M2000F rotating compensator ellipsometer (RCETM) running the WVASE32 software at an angle of incidence of $75,14^{\circ}$. A LEO Supra 35 VP and a PHILIPS CM 20 were used for the SEM and TEM measurements, respectively. $\mathrm{X}$-ray photoelectron spectroscopy was carried out in an ultra-high vacuum system (pressure $<4 \times 10^{-9} \mathrm{mbar}$ ), using a non-monochromatized $\mathrm{Al} \mathrm{K} \alpha(1486.6 \mathrm{eV})$ X-ray source, for XPS measurements, and a hemispherical electron energy analyzer, Leybold EA11 , operating at $100.00 \mathrm{eV}$ pass energy, with an anode power of $240 \mathrm{~W}$; the analyzed area was an approximately $2 \times 5 \mathrm{~mm}^{2}$ rectangle positioned near the geometric center of each sample. All samples were measured as deposited, without any treatment or cleaning before being introduced into the ultra-high vacuum chamber.

\section{Results and discussion}

In Fig. 1 the recorded transmission spectra of a hw $\mathrm{Ta}_{2} \mathrm{O}_{5}$ film deposited on a quartz substrate is shown. The corresponding spectrum of a bare substrate is also shown. It is observed that the $h w \mathrm{Ta}_{2} \mathrm{O}_{5}$ sample is transparent and within the visible range its transmission coincides with the transmission of the substrate alone, indicating a film of high optical quality, without light losses below the band gap, which are usual in transparent metal oxide films. A closer look of the spectra in Fig. 1 shows that in some cases the maxima fall slightly above the transmission of the bare substrate. This is indicative of a film more transparent than the fused silica substrate, i.e., with refractive index smaller than that of the latter.

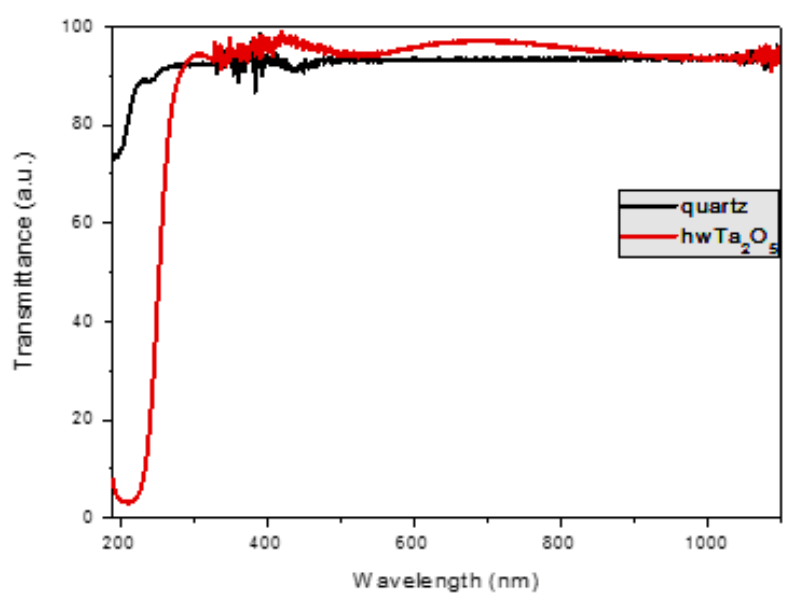

Fig. 1. The recorded transmission spectra of a hwTa $\mathrm{O}_{5}$ film deposited on a quartz substrate is shown. The corresponding spectrum of a bare substrate is also shown.

The high transparency of $h w \mathrm{Ta}_{2} \mathrm{O}_{5}$ films renders difficult the study of their optical properties using optical transmission-reflection measurements, due to the lack of intense, visible, interference fringes in the spectra. Therefore, samples were deposited on $\mathrm{Si}$ substrates and their optical properties were systematically studied by SE measurements of $\Psi$ and $\Delta$ within the photon energy range 1.2 to $4 \mathrm{eV}$. Theoretical spectra were synthesized with the aid of the effective medium approximation (EMA) [34] considering samples composed by database $\mathrm{Ta}_{2} \mathrm{O}_{5}$ and voids and finally fitted to those experimentally recorded. In Fig. 2 (upper) the photon energy variation of the real part of the refractive index of hwTa $\mathrm{O}_{5}$ film is shown.
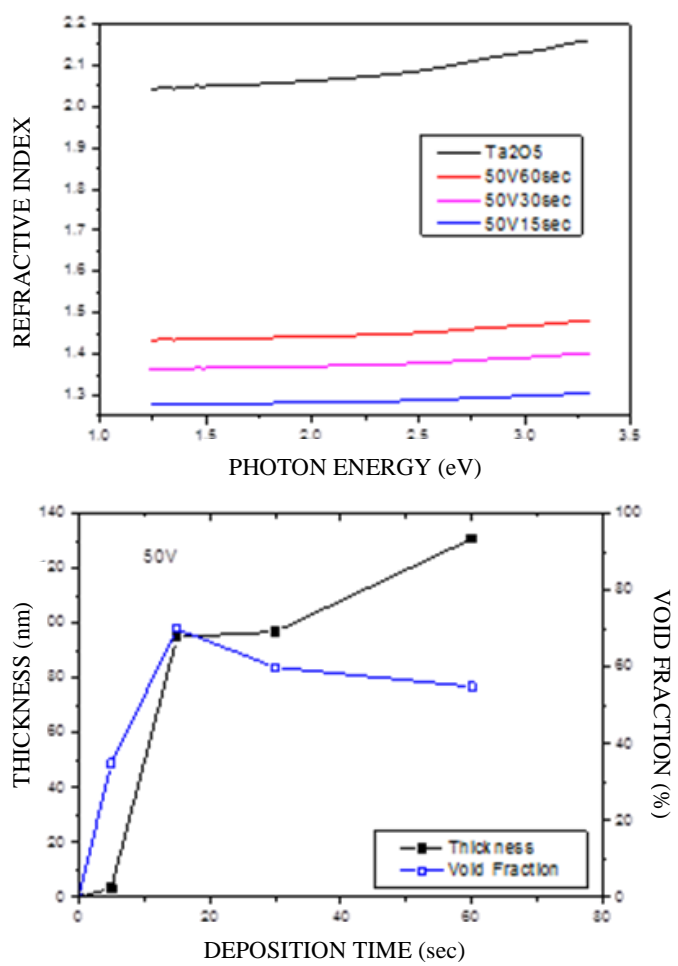

Fig. 2. (Upper) The photon energy variation of the real part of the refractive index of $h w \mathrm{Ta}_{2} \mathrm{O}_{5}$ film. (Lower) The thickness and the void fraction, as obtained from the SE analysis. 
It can be observed that the refractive index of hw $\mathrm{Ta}_{2} \mathrm{O}_{5}$ films exhibit similar variation with that for the database $\mathrm{Ta}_{2} \mathrm{O}_{5}$ film, but is shifted toward lower values. The shift is small for short deposition times and saturates at a value below 1.5. This small value of the refractive index of hwTa $\mathrm{O}_{5}$ films causes their optical transmission and low reflection observed in Fig. 1. The thickness and void fraction, as obtained from the SE analysis, is shown in Fig. 2 (lower). It must be noted that, independently of filament temperature, for thicknesses below approximately $20 \mathrm{~nm}$ the void fraction increases linearly and saturates at values near $60 \%$. These high void fractions, i.e. the high porosity of hw $\mathrm{Ta}_{2} \mathrm{O}_{5}$ films, justify the high optical transmission and low reflection of the corresponding samples seen in Fig. 1. In spite of their high porosity and the low deposition temperature used (room temperature), hw $\mathrm{Ta}_{2} \mathrm{O}_{5}$ films proved to adhere well on many kinds of substrates. Good adhesion was shown to silicon, fused silica and glass, while the corresponding hw $\mathrm{Ta}_{2} \mathrm{O}_{5}$ films were able to bear patterning by lift-off. The above films deposited on organic films were also used for the fabrication of hybrid organic light emission diodes.

In Fig. 3 SEM micrographs taken on the surface of hw $\mathrm{Ta}_{2} \mathrm{O}_{5}$ samples deposited at filament temperatures of $500{ }^{\circ} \mathrm{C}$ are shown. The deposition times of the above films are not the same, thus they have different thicknesses. It can be observed that the samples exhibit a granular surface morphology with voids between grains. The film thicknesses range between 10 and $100 \mathrm{~nm}$ (depending on deposition time), which is larger than the grain size. This indicates a growth preferentially on top of the first deposited grains, which is expected since the deposition occurs at room temperature so species condensing on the surface have low mobility. This tendency continues for thicker films, resulting in grains composed of smaller ones. As the quantity of the superficial oxide on the filament is depleted with deposition time, the growth rate drops to very low values; therefore, this deposition method is not suitable for the deposition of films with thickness above $1000 \mathrm{~nm}$.

A possible reason for the high void fractions exhibited by hw $\mathrm{Ta}_{2} \mathrm{O}_{5}$ films is that the grains seen in Fig. 3 are not compact but they consist of smaller grains, which can be observed in Fig. $\mathbf{3 b}$.
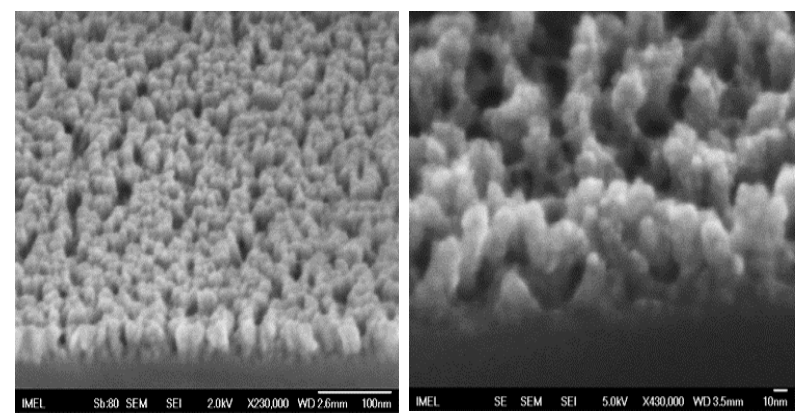

Fig. 3. SEM micrographs taken on the surface of $h w \mathrm{Ta}_{2} \mathrm{O}_{5}$ samples deposited at filament temperatures of $500{ }^{\circ} \mathrm{C}$ at different deposition times.
In order to further investigate the morphology of hw $\mathrm{Ta}_{2} \mathrm{O}_{5}$ films TEM measurements were made.

In Fig. 4A, B TEM images taken on a hwTa $\mathrm{O}_{5}$ sample with thickness of $60 \mathrm{~nm}$ and grown at a filament temperature of $500{ }^{\circ} \mathrm{C}$ are shown. It is observed that the sample is actually composed of spherical grains with dimensions of the order of 5-6 $\mathrm{nm}$. The corresponding electron diffraction pattern exhibits no structure, similarly to XRD spectra taken on hwTa $\mathrm{O}_{5}$ films. This indicates that grains are composed by essentially amorphous material. However, the dark-field TEM image reveals the existence of crystalline regions with dimensions of the order of 1-3 nm in the films. The absence of structure in XRD and electron diffraction patterns can be explained by the small size of crystallites and their random orientation in films. It may be concluded then that hwTa $\mathrm{O}_{5}$ films are essentially composed by amorphous grains with dimensions near 5-6 nm, the center of which is probably occupied by crystalline $\mathrm{Ta}_{2} \mathrm{O}_{5}$, without, however, preferential orientation. Since the depositions were carried out at room temperature, which is not favorable for crystallization, it is reasonable to suppose that the grains observed in Fig. 4 were formed on the heated filament. Such grains then, or clusters of grains, were emitted from the filament and condensed on the substrate.

(a)

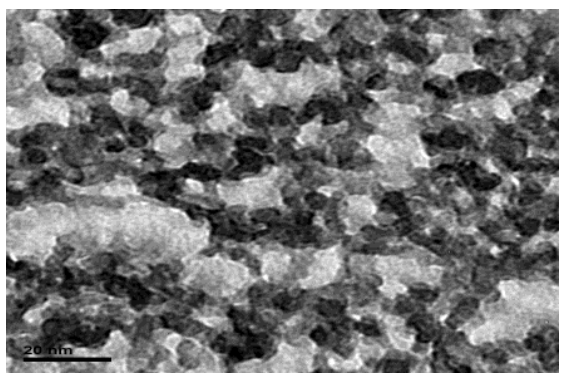

(b)

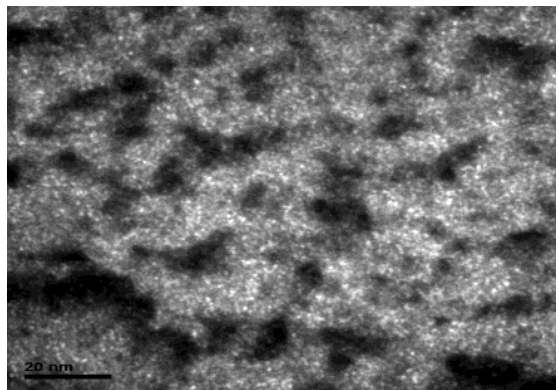

(c)

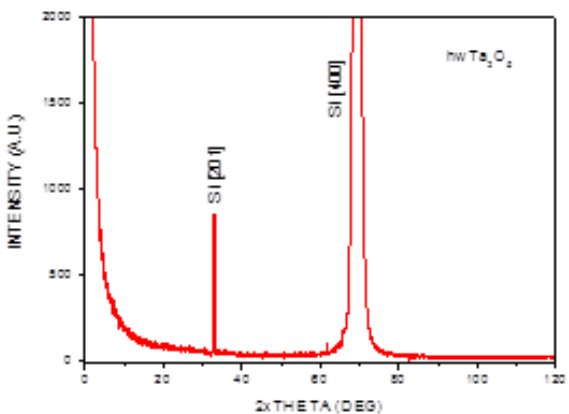

Fig. 4. (A, B). TEM images taken on a hwTa $\mathrm{O}_{5}$ sample with thickness of $60 \mathrm{~nm}$ and grown at a filament temperature of $500{ }^{\circ} \mathrm{C}$. (C) XRD pattern taken on annealed hw $\mathrm{Ta}_{2} \mathrm{O}_{5}$ film. 
As reported before, XRD patterns taken on as deposited hwTa $\mathrm{O}_{5}$ films exhibited no peaks at all. XRD measurements were made on samples after a series of annealing steps for $30 \mathrm{~min}$ in $\mathrm{N}_{2}$ ambient and for various temperatures up to $600{ }^{\circ} \mathrm{C}$. Up to $400{ }^{\circ} \mathrm{C}$ XRD patterns remained structureless; at this temperature weak peaks, indicating enhanced crystallization, started to appear. At even higher annealing temperatures weak, and not well shaped, peaks appear in the XRD patterns (Fig. 4C).

For tantalum oxide films deposited in oxygen environment, for all XPS spectra the Ta4f peak has been analyzed in two doublets with energy separation of $1.9 \mathrm{eV}$, equal full widths at half maximum (FWHM) and an area ratio of $4 / 3$ for $\mathrm{Ta} 4 \mathrm{f} 7 / 2$ to $\mathrm{Ta} 4 \mathrm{f} 5 / 2$ (Fig. 5a). The main peak $\mathrm{Ta} 4 \mathrm{f} 7 / 2$ is at a binding energy of $26.4 \pm 0.1 \mathrm{eV}$ corresponding to oxygen bonded to tantalum in $\mathrm{Ta}_{2} \mathrm{O}_{5}$, in agreement with the literature [29].

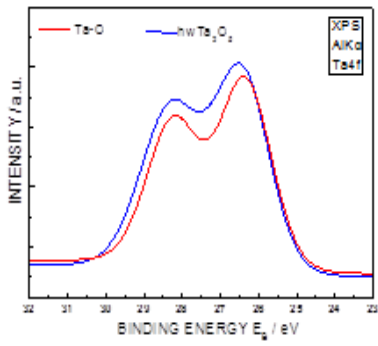

(a)

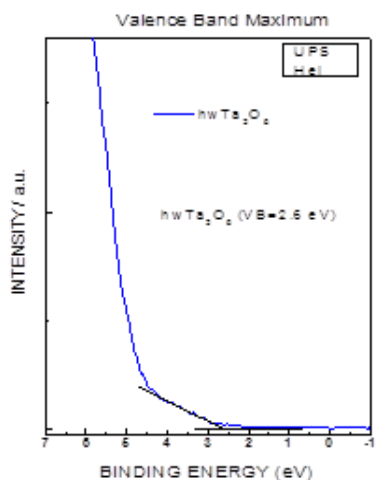

(c)

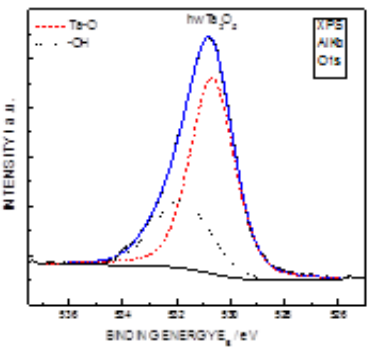

(b)

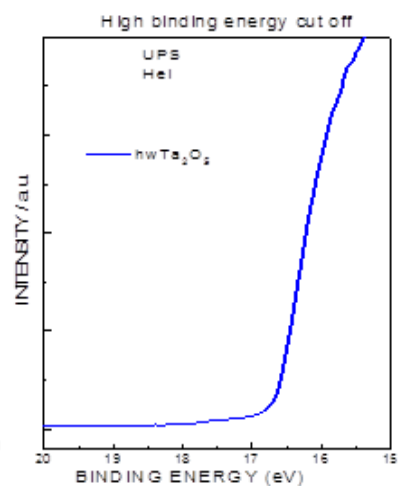

(d)
Fig. 5. XPS spectra for (a) $\mathrm{Ta} 4 \mathrm{f}$ and (b) $\mathrm{O} 1 \mathrm{~s}$ for $\mathrm{hwTa}_{2} \mathrm{O}_{5}$ film. (c) Hel UP Valence band edge spectra and (d) high binding energy cutoff for hwTa $\mathrm{O}_{5}$ film.

In XPS spectra of the same layers (Fig. 5b) the O1s peak has been analyzed in one component at a binding energy of $530.7 \pm 0.1 \mathrm{eV}$ corresponding to oxygen bonded to tantalum in $\mathrm{Ta}_{2} \mathrm{O}_{5}$ in agreement with the literature [29]. The atomic stoichiometry was estimated to be equal to Ta: $\mathrm{O}=1: 2.25\left(\mathrm{Ta}_{2} \mathrm{O}_{5}\right)$. The valence band (VB) of Ta oxide samples appeared at $2.6 \pm 0.1 \mathrm{eV}$, for the oxygen deposited layers. The work function has been estimated from the Fermi level and it was found to be $4.5 \pm 0.1 \mathrm{eV}$, close to the literature reported results for $\mathrm{Ta}_{2} \mathrm{O}_{5}[35]$. The ionization potential value for this film was $8.5 \mathrm{eV}$.

\section{Conclusion}

Summarizing, it was demonstrated that $h w \mathrm{Ta}_{2} \mathrm{O}_{5}$ films deposited at relatively low filament temperatures (up to $600^{\circ} \mathrm{C}$ ) exhibit a high porosity, of the order of $60 \%$ of their volume, because they are composed by grains with dimensions of the order of 5-6 nm, which coalesce to form clusters with dimensions of several tens of $\mathrm{nm}$ increasing with the film thickness. Due to this high porosity, hw $\mathrm{Ta}_{2} \mathrm{O}_{5}$ films exhibit low refractive index values; therefore, they exhibit high optical transmission within the domain of their transparency. The growth of $\mathrm{hwTa} \mathrm{O}_{5}$ films occurs from the condensation of $\mathrm{Ta}_{2} \mathrm{O}_{5}$ vapors produced by the evaporation of the superficial oxide formed on the tantalum filament, which has higher vapor pressure than the metal at these temperatures. Generalizing, it is noted that this simple deposition method can be applied for all metallic oxides having higher vapor pressure than the corresponding metal. hw $\mathrm{Ta}_{2} \mathrm{O}_{5}$ films are stoichiometric, essentially amorphous and retain these characteristics for annealing temperatures up to $400{ }^{\circ} \mathrm{C}$. XPS measurements reveal the stoichiometric character of the deposited films.

\section{Acknowledgements}

We acknowledge support of this work by the project MIS 5002567, implemented under the "Action for the Strategic Development on the Research and Technological Sector", funded by the Operational Programme "Competitiveness, Entrepreneurship and Innovation" (NSRF 2014-2020) and co-financed by Greece and the European Union (European Regional Development Fund).

\section{References}

1. Choi, J. H.; Mao, Y.; Chang, J. P., Materials Science and Engineering, 2011, 72, 97.

2. Robertson, J.; Wallace, R. M., Materials Science and Engineering, 2015, 88, 1.

3. Wilk, G. D.; Wallace, R. M.; Anthony, J. M., J. Appl. Phys., 2001, 89, 5243 .

4. Kim, M. S.; Ko, Y. D.; Yun, M.; Hong, J. H.; Jeong, M. C.; Myoung, J. M.; Yun, I., Mater. Sci. Eng., 2005, 123, 20.

5. Consiglio, S.; Papadatos, F.; Naczas, S.; Skordas, S.; Eisenbraun, E. T.; Kaloyeros, A. E., J. Electrochem. Soc., 2006 153, F249.

6. Quan, Y. C.; Lee, J. E.; Kang, H.; Roh, Y.; Jung, D.; Yang, C.W., Jpn. J. Appl. Phys. 2002, 141, 6904 .

7. Lee, K.; Jang, W.; Kim, H.; Lim, H.; Kim, B.; Seo, H.; Jeon, H., Thin Solid Films, 2018, 657, 1.

8. Sayan, S.; Nguyen, N. V.; Ehrstein, J.; Emge, T.; Garfunkel, E.; Croft, M.; Zhao, X.; Vanderbilt, D.; Levin, I.; Gusev, E. P; Kim, H.; Mclntyre, P. J., Appl. Phys. Lett., 2005, 36, 152902.

9. Kim, J. H.; Ignatova, V. A.; Heitmann, J.; Oberbeck, L., J. Phys. D. Appl. Phys., 2008, 41, 172005.

10. Hino, T.; Nishida, M.; Araki, T., Surface and Coatings Technology, 2002, 149, 1 .

11. Boughaba, S.; Islam, M. U.; Sproule, G. I.; Graham, M. J., Surface and Coatings Technology, 1999, 757, 120.

12. Chaneliere, C.; Autran, J. L.; Devine, R. A. B.; Balland, B., Mater. Sci. Eng., 1998, 22, 269.

13. Ezhilvalavan, S.; Tseng, T. Y., Journal of Mater. Sci.: Materials in Electronics, 1999, 10,9.

14. Tu, Y. K.; Lin, C. C.; Wang, W. S.; Huang, S. L.; in Batchman, E.; Carson, R. F.; Galawa, R. L.; Wojtunik, H. J.; (Eds.), SPIE Proc. SPIE, Bellingham, WA, 1987, 836, 40.

15. Takahashi, H.; Suzuki, S.; Nishi, I., J. Lightwave Technol. 1994, 126, 989.

16. Chu, A. K.; Lin, H. C.; Cheng, W. H., J. Electron. Mater., 1997, 26,889 . 
17. Traylor-Kruschwitz, J. D.; Pawlewicz, W. T.; Appl. Opt., 1997 36, 2157.

18. Chaneliere, C.; Four, S.; Autran, J. L.; Devine, R. A. B.; Balland, B.; Sandler, N. P., Journal of Applied Physics, 1998 83, 4823.

19. Balliou, A.; Papadimitropoulos, G.; Skoulatakis, G.; Kennou, S.; Davazoglou, D.; Gardelis, S.; Glezos, N., ACS Appl. Mater. Interfaces, 2016, 8, 7212 .

20. Motohiro, T.; Taga, Y., Appl. Opt., 1989, 28, 2466.

21. Kumara, M.; Kumaria, N.; Kumara, V. P.; Karara, V.; Sharma, A. L., Materials Today: Proceedings, 2018, 5, 3764.

22. Hermann Jr., W.C., J. Vac. Sci. Technol., 1981, 18, 1303.

23. Boughaba, S., Sproule, G. I.; McCaffrey, J. P.; Islam, M.; Graham, M. J., Thin Solid Films, 2000, 358, 104.

24. Shinriki, H.; Nakata, M., IEEE Trans. Electron Devices, 1991, $38,455$.

25. McKinley, K. A.; Sandler, N. P., Thin Solid Films, 1996, 440, 290.

26. Shinriki, H.; Sugiura, M.; Shimomura, K.; Nakajima, T., J. Electrochem. Soc., 1998, 145, 3247.

27. Zhang, J. Y.; Lim, B.; Boyd, I. W.; Dusastre, V., Appl. Phys. Lett., 1998, 73, 2299.

28. Shinriki, H.; Kisu, T.; Kimura, S.-I.; Nishioka, Y.; Kawamoto, Y.; Mukai, K., IEEE Trans. Electron Devices, 1990, 37, 1939.

29. Atanassova, E.; Spassov, D., Appl. Surf. Sci., 1998, 135, 71.

30. Natishan, P. M.; McCafferty, E.; Puckett, P.R.; Michel, S., Corros. Sci., 1996, 38, 1043.

31. Hashimoto, T.; Yoko, T., Appl. Opt., 1995, 34, 2941.

32. Zhang, J. Y.; Bie, L. J.; Boyd, I. W., Jpn. J. Appl. Phys., Part 2 , 1998, 37, L27.

33. Kukli, K.; Aarik, J.; Aidla, A.; Kohan, O.; Uustare, T.; Sammelselg, V., Thin Solid Films, 1995, 260, 135.

34. Bruggeman, D., Ann. Phys. Leipz., 1935, 24, 636.

35. Chun, W. J.; Ishikawa, A.; Fujisawa, H.; Takata, T.; Kondo, J. N.; Hara, M.; Kawai, M.; Matsumoto, Y.; Domen, K., J. Phys. Chem. B, 2003, 107, 1798. 